\title{
Configuraciones de la laicidad en los debates por la legalización del aborto en la Argentina: discursos parlamentarios y feministas (2015-2018)
}

\author{
Configurations of secularism in debates about the \\ legalization of abortion in Argentina: parliamentary and \\ feminist discourses (2015-2018)
}

Karina Felitti ${ }^{1}$, Sol Prieto ${ }^{2}$

${ }^{1}$ Doctora en Historia. Investigadora adjunta, Consejo Nacional de Investigaciones Científicas y Técnicas, con sede en Instituto Interdisciplinario de Estudios de Género, Facultad de Filosofía y Letras, Universidad de Buenos Aires; Ciudad Autónoma de Buenos Aires, Argentina. $\triangle$ (iD)

${ }^{2}$ Doctora en Ciencias Sociales. Becaria posdoctoral, Consejo Nacional de Investigaciones Científicas y Técnicas, con sede en Centro de Estudios e Investigaciones Laborales. Ciudad Autónoma de Buenos Aires, Argentina. $\triangle$ (iD)
RESUMEN Este artículo indaga en las configuraciones de laicidad presentes en el debate parlamentario sobre el proyecto de interrupción voluntaria del embarazo en 2018 y en algunos espacios específicos del activismo feminista en los que se discute y promueve la laicidad, relevados entre 2015 y 2018. A partir del análisis de las versiones taquigráficas de los discursos de diputados/as y senadores/as, y las observaciones participantes en encuentros de mujeres y/o feministas, analizamos las ideas que emergen sobre la relación entre Estado, iglesias, religiones, espiritualidades y democracia cuando se discuten y/o promueven derechos sexuales y reproductivos. Los resultados permiten confirmar la hipótesis sobre la profundización de la presencia del discurso de la laicidad en ambas Cámaras durante 2018, con diferentes definiciones e intensidades, y la ampliación de los apoyos a las campañas ya existentes por el Estado laico en los espacios feministas; y, en paralelo, la problematización de una identidad feminista, religiosa y/o espiritual confluyente.

PALABRAS CLAVES Aborto; Legislación; Feminismo; Argentina.

ABSTRACT This article explores the configurations of secularism present in the parliamentary debate on the voluntary termination of pregnancy bill in 2018, and in some specific areas of feminist activism in which secularism is discussed and promoted, collected in the period between 2015 and 2018. Based on the official transcriptions of the speeches of deputies and senators during the debates as well as participant observation in national and regional women's and feminist gatherings, we analyze the ideas that emerge in relation to the State, churches, religions, spiritualities and democracy when sexual and reproductive rights are discussed. The results confirm our hypothesis regarding the expansion of the discourse on secularism in both Chambers during 2018, with different definitions and intensities, as well as the amplification of support for existing feminist campaigns for a secular State and, in parallel, new problematizations regarding the confluence of a feminist identity with religious and/or spiritual identity.

KEY WORDS Abortion; Legislation; Feminism; Argentina. 


\section{INTRODUCCIÓN}

El 6 de marzo de 2018 la Campaña Nacional por el Derecho al Aborto Legal Seguro y Gratuito (en adelante, la Campaña) presentó por séptima vez su proyecto de ley de Interrupción Voluntaria del Embarazo (IVE) al Congreso Nacional. Luego de intensas jornadas de debate, la Cámara de Diputados lo aprobó en la mañana del 14 de junio (129 a favor, 125 en contra, una abstención), pero el 8 de agosto no logró la mayoría en la Cámara de Senadores (38 en contra y 31 a favor, dos abstenciones y una ausencia). Pese a esto, la relevancia que tomó el tema en la opinión pública permite pensar que se dio un cambio en la percepción social del aborto, una mayor apertura para su discusión, una circulación amplia de los argumentos a favor y en contra y la posibilidad de visibilizar la adhesión a una postura. Por ejemplo, el uso del pañuelo verde, símbolo distintivo de la Campaña -que fue usado por primera vez en el Encuentro Nacional de Mujeres de 2003- se hizo masivo y, en 2018, miles de mujeres comenzaron a Ilevarlo anudado en sus mochilas y continúan haciéndolo. A partir de esta masivización surgió su contrapunto, el pañuelo celeste con el eslogan de "Salvemos las dos Vidas", de uso más coyuntural y efímero. Grupos de actrices, estudiantes, cantantes, manifestaron su posición favorable a la legalización, sumándose a históricas activistas feministas, quienes habían también ampliado sus bases discursivas y políticas al proponer el derecho a la interrupción voluntaria del embarazo a las personas con capacidad de gestar y de esa forma incluir a varones trans.

Las explicaciones más recurrentes sobre el fracaso del proyecto pusieron el acento en las presiones del Vaticano y el rol del papa Francisco en la política nacional, y la falta de laicidad del Estado. Este diagnóstico, ya presente en espacios feministas y de diversidad sexual, amplió sus alcances y produjo su propio símbolo de circulación pública: un pañuelo naranja o negro -por un debate sin consenso sobre los colores- que lleva la consigna "Iglesia y Estado, asunto separado". Este pañuelo llegó a las calles y al prime time televisivo, de la mano de actrices que apoyan la legalización del aborto y también esta consigna. Esta visibilidad hizo que la laicidad del Estado fuera discutida más allá de ámbitos académicos y activismos que llevaban un tiempo haciéndolo -por ejemplo, la Coalición Argentina por un Estado Laico (CAEL) a la que adhieren diferentes agrupaciones, colectivos y personas- y configuró una aspiración de sectores más amplios de la sociedad, incluyendo a funcionarios estatales y representantes religiosos. Un ejemplo fue la mayor convocatoria que tuvieron las apostasías colectivas organizadas en diferentes lugares del país después del rechazo del proyecto de interrupción voluntaria del embarazo en la Cámara de Senadores. De este modo la consigna por la laicidad se transformó en algo más que una estrategia discursiva ${ }^{(1)}$ y llevó a muchas personas a una acción concreta, en la que también se aclaró que no se trataba de un acto de rechazo a las creencias sino al entrometimiento de la Iglesia católica en este y otros temas de política sexual y de género.

El objetivo de este artículo es reconstruir las configuraciones de laicidad que emergieron en el debate parlamentario del proyecto de interrupción voluntaria del embarazo, el 13 y 14 de junio en la Cámara de Diputados y el 8 de agosto en la Cámara de Senadores en 2018; y las discusiones sobre la laicidad en algunos espacios específicos del activismo feminista. En ambos espacios, nos interesa especificar cuáles son las ideas sobre la relación entre Estado, iglesias, religiones y democracia que se ponen en juego en debates sobre derechos sexuales y reproductivos. El argumento de este artículo es que la apelación al discurso de la laicidad en el debate parlamentario sobre interrupción voluntaria del embarazo dio continuidad a un lugar de enunciación ya presente en el tratamiento de otras leyes relacionadas con la autonomía corporal y la libertad sexual, y que intensificó su presencia entre quienes votaron a favor y apareció también en algunos votos en contra. Por otro lado, la mayoría negativa en la Cámara de Senadores Ilevó la consigna 
por el Estado laico más allá de los activismos específicos, y profundizó el debate en los feminismos sobre la posibilidad de tener una religión o espiritualidad y ser feminista.

\section{ACERCA DE LA INVESTIGACIÓN}

Las fuentes de análisis utilizadas para este trabajo fueron: a) las argumentaciones de diputadas/os y senadoras/as durante las dos sesiones en las que se discutió y votó el proyecto de interrupción voluntaria del embarazo, y b) los registros en talleres específicos (sobre laicidad, religiones, espiritualidades, etc.) y espacios masivos (acto de apertura y cierre, marchas, ferias) de tres encuentros nacionales de mujeres $\left(30^{\circ}\right.$ Encuentro Nacional de Mujeres de Mar del Plata, provincia de Buenos Aires, del 10 al 12 de octubre de 2015; el $31^{\circ}$ Encuentro Nacional de Mujeres de Rosario, provincia de Santa Fe, del 8 al 10 de octubre de 2016; y el $32^{\circ}$ Encuentro Nacional de Mujeres de Resistencia, provincia de Chaco, del 14 al 16 de octubre de 2017) y dos Encuentros Regionales de Mujeres, Lesbianas, Travestis y Trans (ERMLTT) $\left(20^{\circ}\right.$ ERMLTT de Morón, provincia de Buenos Aires, el 9 de septiembre de 2017 y el $21^{\circ}$ ERMLTT de La Matanza, provincia de Buenos Aires, el 8 de septiembre de 2018). Tomamos estos espacios por la importancia que han ido ganando desde 1986 en cuanto a poder de convocatoria -70.000 participantes en 2017-, visibilidad en los medios masivos de comunicación y capacidad de definir agendas y estrategias políticas, como en el caso de la Campaña Nacional por el Derecho al Aborto Legal Seguro y Gratuito cuyas "simientes" -según la información provista por la misma Campaña- se ubican en los encuentros de 2003 y $2004^{(2,3)}$.

Seguimos una estrategia cualitativa que conjuga técnicas de análisis del discurso (más específicamente, análisis de contenidos) y de observación participante, y hacemos explícita la reflexividad que implicó este registro en eventos en los cuales coincidía nuestro rol como investigadoras, feministas y militantes del aborto legal. En el caso de los espacios feministas preservamos la identidad de las participantes y en el caso de las y los legisladores, citamos sus nombres, bloques y distritos dado que sus exposiciones fueron públicas. Consideramos la definición de discurso social de Angenot, como:

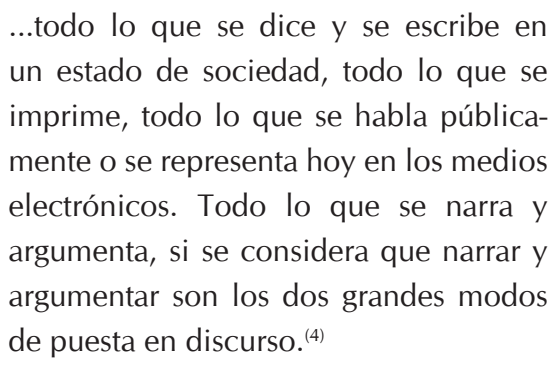
un estado de sociedad, todo lo que se imprime, todo lo que se habla públicamente o se representa hoy en los medios electrónicos. Todo lo que se narra y argumenta, si se considera que narrar y argumentar son los dos grandes modos de puesta en discurso. ${ }^{(4)}$

En la primera parte, introducimos algunos antecedentes para ubicar la presentación del proyecto de interrupción voluntaria del embarazo en el parlamento y nuestro enfoque: a) marco legal y oficioso de la práctica, rol de los feminismos y de los activismos religiosos; b) definiciones de laicidad y aportes de los estudios de género; y c) la evolución de las discusiones recientes en la Argentina en torno a cuestiones vinculadas a la autonomía de las personas sobre sus cuerpos. En la segunda parte, exponemos el análisis de las fuentes: a) las concepciones de la laicidad presentes en los debates sobre la interrupción voluntaria del embarazo en las sesiones de las Cámaras de Diputados y Senadores; y b) los modos en que se entiende la laicidad en los encuentros de mujeres $y / o$ feministas relevados. Por último, nuestras conclusiones permiten dar cuenta de las relaciones diversas entre Estado laico y derechos sexuales y reproductivos, en un momento en el cual las discusiones sobre la laicidad rebasan los ámbitos intelectuales y de activismos específicos.

\section{ANTECEDENTES}

\section{Situación del aborto y abordajes}

El Código Penal de 1921 estableció la ilegalidad del aborto y dos situaciones en las que no es considerado punible: si tiene el fin de 
evitar un peligro para la vida o la salud de la "madre" y si el embarazo proviene de una violación o de un atentado al pudor cometido sobre una mujer idiota o demente (artículo 86). Si bien esta normativa sigue vigente, en 2004, el Ministerio de Salud de la Nación publicó una "Guía para el mejoramiento de la atención post-aborto" y en 2007 un protocolo de atención de embarazos no punibles, que se actualizó en 2015. En esta última versión se incluyó el fallo de la Corte Suprema de Justicia de 2012 que aclara que toda mujer que resultara embarazada como producto de una violación debe tener acceso a un aborto no punible sin necesidad de intervención judicial. Este fallo exhortó, a su vez, a que cada jurisdicción redactase su propio protocolo de atención $y$, aunque varias jurisdicciones no lo han hecho, resultó un avance en un contexto todavía restrictivo ${ }^{(5,6)}$.

Además de los abortos no punibles que se realizan en el sistema de salud, las organizaciones feministas y sociales fueron pioneras en informar y acompañar a las mujeres durante la interrupción voluntaria de sus embarazos con misoprostol. Se destacan en esta historia la línea telefónica "Más información, menos riesgo" que creó, en 2009, la agrupación Lesbianas y Feministas por la Descriminalización del Aborto; y su manual Todo lo que querés saber sobre cómo hacerse un aborto con pastillas; así como el trabajo de las Socorristas en red (feministas que abortamos) y su impulso por parte de la Colectiva La Revuelta de la provincia de Neuquén ${ }^{(7)}$, entre otras redes de solidaridad y acompañamiento que, con mayor o menor grado de institucionalización, siguen extendiéndose.

Respecto a los estudios sobre el aborto, la bibliografía es extensa y enfoca en diferentes aspectos: el aborto como problema de salud pública, cuestión de derechos, de justicia, de ciudadanía, con relación a los feminismos y las experiencias de las mujeres que interrumpen voluntariamente sus embarazos. En los análisis que cruzan aborto y religiones no siempre la laicidad del Estado es el eje central: algunos relevan los posicionamientos de las jerarquías religiosas en el espacio público y su lobby parlamentario, el papel de los activismos conservadores como las organizaciones no gubernamentales que se definen como Pro Vida ${ }^{(8,9,10,11,12,13,14)}$, el rol de la Bioética y de la objeción de conciencia ${ }^{(15,16)}$, así como el papel que tiene el papa Francisco en el escenario local ${ }^{(17,18)}$. Varios estudios reconocen aportes desde el campo religioso al activismo por la legalización ${ }^{(9,19)}$, la incidencia de una renovada oferta espiritual en este tema ${ }^{(20)}$ y los procesos de resignificación de creencias de mujeres religiosas que deciden abortar $^{(21,22)}$. Este artículo dialoga especialmente con este conjunto de trabajos.

\section{Tipos de laicidad y aportes desde el enfoque de género}

Entre los análisis conceptuales del término "laicidad", reconocemos tres grandes discusiones: 1) si cabe distinguir la idea de "secularización" -que refiere a la autonomía de la esfera política respecto de la religiosa en un sentido amplio- de la idea de "laicidad" en el campo exclusivamente político-estatal; 2) si la laicidad debe ser entendida desde el punto de vista de las instituciones formales o si debe incluir, además, la esfera de las instituciones y normas políticas informales; 3 ) si el enfoque de la laicidad debe hacer eje en la intervención del Estado sobre el campo religioso o en la intervención de las instituciones religiosas sobre el Estado ${ }^{(23)}$.

En el marco de estos debates, para Mi$\operatorname{lot}^{(24)}$ la laicidad es un concepto que refiere al arreglo particular en un momento determinado entre Estado e iglesias, en el cual el poder político no se apoya en símbolos y poderes religiosos para obtener su legitimidad. En esta relación se dan tres "principios": separación, neutralidad, y libertad de conciencia y religión. Este arreglo puede manifestarse en distintos tipos: laicidad separatista, anticlerical, autoritaria, de fe cívica, de reconocimiento y de colaboración.

Para el caso argentino, Esquivel ${ }^{(25)}$ propone el modelo de laicidad subsidiaria, que se da en la convivencia de políticas nacionales de mayor autonomía civil y estatal con respecto a las instituciones religiosas, junto 
con resabios de institucionalidades previas. Es decir, supone el correlato de un Estado con una fuerte matriz católica en su génesis e historia que, a su vez, coexiste con procesos de democratización y secularización que habilitan la emergencia de reconocimientos a los formatos plurales de las sociedades contemporáneas. Si bien esta definición presenta variaciones en las provincias ${ }^{(26,27,28)}$, la participación de agentes, dispositivos y discursos católicos en el diseño y la implementación de determinadas políticas públicas en todo el país confirma la presencia de este tipo de laicidad.

En este artículo adherimos a esta definición de laicidad subsidiaria y, para definir la situación actual de Argentina siguiendo los aportes de $\mathrm{S} c o t t^{(29)}$, asumimos una posición crítica a la idea de que los Estados laicos son indefectiblemente garantes de derechos sexuales y reproductivos. El abordaje que hace esta autora desde la historia $-\mathrm{y}$ la denuncia de las implicancias de la prohibición del velo musulmán en la Francia contemporáneamuestra cómo el corrimiento de la religión como base de legitimidad de los Estados modernos no aseguró la igualdad entre varones y mujeres, sino que la secularización -que comparte con la laicidad la idea de autonomización entre Iglesia y Estado- construyó un modelo binario en el que lo público, ligado al mercado y la política, la razón y la burocracia se asoció a los varones; y, lo privado, relacionado con el cuidado de la familia y la reproducción, la espiritualidad, los afectos y la intimidad se adjudicó a las mujeres. Como afirma Scott, en lugar de argumentos bíblicos, los filósofos de la modernidad se apoyaron en la medicina $-y$, en particular, en la ginecología- para sostener un modelo diferencial que, bajo la propuesta de complementariedad entre dos sexos, consolidaba la desigualdad.

De un modo similar, en América Latina la creación de oficinas públicas para el registro civil de matrimonios y nacimientos confirmaron un modelo de familia patriarcal, un orden de género y moral que expresaba el matrimonio heterosexual, monógamo e indisoluble, y la autoridad del marido sobre la esposa y la descendencia. En ese sentido, la aprobación reciente en algunos países de normativas que garantizan el matrimonio entre personas del mismo sexo, no debería considerarse una consecuencia necesaria de la laicidad o de una de sus expresiones -la separación del Estado y la Iglesia-, sino el resultado de las luchas movimientos sociosexuales que demandan políticas de distribución y reconocimiento ${ }^{(1,30)}$. Vaggione y Jones $^{(31)}$, en su análisis sobre los posicionamientos en el debate legislativo sobre matrimonio igualitario en 2010, a la hora de emitir sus votos y justificarlos dan cuenta de estas distinciones entre el uso de argumentos privados y públicos y no solo entre discursos religiosos o seculares. Algunos de estos cruces se repitieron en el tratamiento del proyecto de interrupción voluntaria del embarazo, como veremos más adelante.

\section{Concepciones de laicidad en otros debates legislativos recientes}

A partir de la recuperación de la democracia, la agenda de derechos humanos fue incluyendo temas de política sexual, familiar y de género, y abrió la discusión sobre el lugar que el Estado debía dar a la Iglesia católica en estos temas de orden público. Al debate legislativo y social sobre la ley de divorcio en $1987^{(32)}$ le siguieron otros, sobre salud sexual y procreación responsable, educación sexual integral y matrimonio igualitario, entre otros. En este caso, la oposición religiosa al proyecto -tanto católica, como evangélica- se movilizó en el espacio público y tuvo un fuerte aval del entonces arzobispo de Buenos Aires, Jorge Mario Bergoglio, que comparó el proyecto con "una movida del Padre de la Mentira que pretende confundir y engañar a los hijos de Dios"(33). Si bien la ley se aprobó en una votación ajustada, dejó en evidencia que la Iglesia católica, aunque tiene un papel importante desde el punto de vista de las coaliciones sociales (advocacy coalitions) no necesariamente define los resultados. Asimismo, Vaggione y Jones ${ }^{(31)}$ mostraron cómo lo religioso también fue movilizado a favor del matrimonio igualitario, con alianzas 
entre activismo LGBT y determinados actores religiosos y el uso que hicieron algunos/as legisladores/as de su identidad religiosa para votar a favor del proyecto.

Otros casos en los que la Iglesia católica tuvo insuficiente poder de veto fueron la Ley 26742 de 2012, titulada "Derechos del Paciente, Historia Clínica y Consentimiento Informado" y conocida popularmente como "Ley de muerte digna"(34); la Ley 26862 de 2013, conocida como "Ley de fecundación asistida"(15) y la Ley 16743, conocida como "Ley de identidad de género" de 2012. Al analizar los discursos en torno a la laicidad, puestos en juego en estos debates, Prieto ${ }^{(35)}$ observó que los/as legisladores/as utilizan un vocabulario secular en comparación con el campo semántico desplegado por los agentes religiosos, sobre todo católicos, en las diferentes instancias de debate tales como audiencias y declaraciones públicas. En muchos casos, postulan una "emancipación" ciudadana de las decisiones estatales sobre cuestiones privadas e íntimas, traducida en un lenguaje de derechos. En estos debates, quienes votaron a favor de estas leyes y de la reforma del Código Civil reclamaron para sí un reconocimiento histórico como artífice de esta ampliación inédita de derechos con frases como "hoy tenemos el privilegio de ser parte de la historia", "de votar algo histórico" o "de saldar una deuda histórica". La idea de laicidad con mayor presencia fue la que se enfoca en la separación entre el campo político y el religioso, y destaca la autonomía del primero respecto del segundo, sin hacer hincapié en fenómenos como el pluralismo religioso o la igualdad de cultos.

\section{ANÁLISIS \\ Concepciones de laicidad en los debates en la Cámara de Diputados y de Senadores sobre el proyecto de interrupción voluntaria del embarazo, en 2018}

En la sesión de la Cámara de Diputados hubo 15 discursos con menciones o referencias a la laicidad, a partir de expresiones como "Estado laico" o "sociedad laica". De los 15 legisladores y legisladoras que se refirieron al tema, 14 se pronunciaron a favor del proyecto y una en contra. En la sesión del Senado hubo 11 discursos que se refirieron a la laicidad utilizando expresiones como "Estado laico", "convicciones laicas", "laicismo", etcétera. De los 11 legisladores y legisladoras que se refirieron al tema, siete se pronunciaron a favor del proyecto, tres en contra, y una se abstuvo. Los marcos o encuadramientos a través de los cuales apareció la laicidad fueron seis, los cuales son presentados a continuación, en un orden que no propone una jerarquización sino facilitar la lectura.

En primer lugar, la laicidad aparece enmarcada como una obligación que tienen en tanto legisladoras/es de ratificar un estado de cosas que ya existe. Parten de la idea de que el Estado argentino es laico (algunos consideran que esto se inscribe en la Constitución) y, por lo tanto, votar a favor de la ley implica ratificar esa laicidad y cumplir con un mandato constitucional. En ese sentido, refuerzan lo que Mallimaci explica a partir del "mito de la república laica", cuya construcción continua desde 1880 es amenazada por una construcción imaginaria de nación católica, orgánica, comunitarista y conservadora desde, aproximadamente, la década de $1920^{(36)}$.

En general, ratificar la laicidad implica un desdoblamiento entre sus creencias individuales y "el bien común", que se resuelve a partir de la idea de que su legitimidad como diputados/as surge del voto popular y, por lo tanto, deben legislar para toda la sociedad y no solo para un sector. Este marco de comprensión implica la privatización de las creencias religiosas y, en ese sentido, es un encuadre que comparte varios elementos con las teorías sociológicas clásicas en torno a la secularización y los discursos sobre la laicidad heredados de la Revolución Francesa. Este marco secular es el que también permite votar en contra del proyecto, ya que no se exponen razones de orden personal -creencias religiosas- sino la obligación estatal de defender los derechos humanos, en este caso, del no nacido. 
Cabe aclarar que todas las citas de este apartado corresponden al Diario de Sesiones de la Honorable Cámara de Diputados de la Nación del 13 de junio $2018^{(37)}$ y al Diario de Sesiones del Senado del 8 de agosto del mismo año ${ }^{(38)}$.

Estamos tratando un tema de salud pública que no puede ser abordado con anteojeras ni morales ni éticas ni ideológicas ni, mucho menos, religiosas. Somos diputados y diputadas que tenemos la obligación de legislar para un Estado laico, garantizando derechos. (Diputada nacional Mayra Soledad Mendoza; bloque: Frente para la Victoria; distrito: Buenos Aires; voto: a favor)

Importa también que nos podamos ubicar como un Estado laico, que es lo que somos $y$, entonces, pensar que las distintas creencias religiosas son parte de nuestra cultura y para muchas personas pueden ser discursos e instituciones fundamentales, pero no lo son para todos y para todas. (Diputada nacional Mónica Macha; bloque: Frente para la Victoria; distrito: Buenos Aires; voto: a favor)

Entre nosotros prima la certeza de que nuestra función es representar la voluntad ciudadana de un Estado laico [...] para lo cual dejamos en la puerta del Congreso nuestras creencias religiosas e incluso nuestras experiencias personales. (Diputado nacional Leopoldo Raúl Guido Moreau; bloque: Frente para la Victoria; distrito: Buenos Aires; voto: a favor)

Es importante diferenciar las convicciones personales ya que todas son respetables de lo que debe ser una política pública de salud en un Estado laico [...] Las políticas públicas en salud no pueden ser determinadas por la doctrina [...] aun para quienes no lo tomamos como una opción ética. (Diputado nacional Marcelo Germán Wechsler; bloque: Propuesta Republicana (PRO); distrito: Ciudad de Buenos Aires; voto: a favor)
No entendieron que vivimos en un Estado laico y que no podemos legislar desde nuestras convicciones porque forman parte de la vida privada de cada uno de nosotros. (Diputada nacional María Teresita Villavicencio; bloque: Evolución Radical; distrito: Tucumán; voto: a favor)

Yo respeto las creencias, pero para mí las creencias tienen que ver con mi fuero íntimo, con mi derecho a la privacidad. Yo soy un hombre de fe. Yo soy un hombre que pertenezco a la religión católica [...], pero diferencio la creencia del rol del Estado, porque me formé en un partido que tiene una visión laica. $Y$ en esa visión laica, la opinión mayoritaria o una creencia mayoritaria no puede imponerse al conjunto de la sociedad. (Senador nacional Luis Petcoff Naidenoff; bloque: Cambiemos; distrito: Formosa; voto: a favor)

Como Congreso, creo que la mayoría de nosotros, en nuestro rol de legisladores, entendemos que debemos respetar nuestra condición de Estado laico; que debemos sancionar leyes que contemplen las expresiones de toda la sociedad. (Senadora nacional Gladys González; bloque: Cambiemos; distrito: Buenos Aires; voto: a favor)

En el curso de los debates en el plenario, se ha dicho que la fuente laica de la moralidad en nuestra sociedad son los derechos humanos. Bueno, señor presidente, si esto es así, seguramente el derecho humano a la vida es el capítulo inicial. (Senador nacional Mario Raymundo Fiad; bloque: Unión Cívica Radical; distrito: Jujuy; voto: en contra)

La historia se va construyendo en un Estado laico y en buena hora que en 1853 empezó a construirse un Estado laico y empezó el Estado a hacerse cargo de muchas de las cosas que hasta entonces se hacía cargo la iglesia. (Senador nacional Dalmacio Mera; bloque: Partido Justicialista; distrito: Catamarca; voto: en contra) 
En segundo lugar, la laicidad aparece como aspiración. A diferencia del marco que la entiende como algo ya dado que debe protegerse, la laicidad del Estado es algo deseable que aún no se alcanzó. En ese sentido, aprobar el proyecto contribuye a este proceso de laicización, que es visto como producto de una pelea por parte del colectivo de mujeres y, a la vez, como una forma no "hipócrita" (sic) de elaborar políticas públicas. La hipocresía denunciada por estos discursos consiste en pasar por alto la existencia de abortos clandestinos que ponen en riesgo la salud de las mujeres. Algunos ejemplos pueden verse a continuación:

\begin{abstract}
Después de doce años y de siete presentaciones, después de muchos encuentros de mujeres, después de debates, de reflexiones, del movimiento de los secundarios que empezó con fuerza en la Argentina para no parar, estamos en el recinto. Estamos acá, en el lugar donde se construyen las políticas públicas, las políticas del Estado laico que queremos ser, las leyes pensadas para regir la vida de todos los argentinos y, en este caso, la de las mujeres y las personas gestantes. (Diputada nacional Brenda Lis Austin; bloque: Unión Cívica Radical; distrito: Córdoba; voto: a favor)
\end{abstract}

Quiero dejar planteado mi voto por un Estado laico que claramente corra el velo de la hipocresía con el que se analizan estos temas. (Diputada nacional Carlos Fernández; bloque: Unión Cívica Radical; distrito: Buenos Aires; voto: a favor)

En tercer lugar, la laicidad estatal aparece como una herramienta transformadora de las políticas públicas y las sociedades en un sentido más democrático y plural. Desde este marco, votar a favor del proyecto implicaría laicizar el Estado y generar políticas públicas que contemplen a sujetos más diversos y distribuyan los bienes públicos en una clave más democrática; ese Estado más plural y democrático aparece como una oportunidad para construir una sociedad del mismo tipo.
En estos discursos la laicidad es pensada como un acuerdo de convivencia promovido por el Estado pero que trasciende a lo estatal y se derrama sobre la sociedad civil. De este modo, va más allá de la separación entre la esfera política y las convicciones religiosas, y es entendida en el marco de la democracia.

Debemos construir un Estado, laico, que contemple todas las miradas la pluralidad, todas las visiones acerca de la vida [...] lograr un Estado que sea plural, democrático, que nos incluya a todos, porque allí radica su riqueza [...] Hablemos de pluralidad, porque esas miradas integristas pueden ser las semillas de las visiones más totalitarias. (Diputado nacional Hugo María Marcucci; bloque: Unión Cívica Radical; distrito: Santa Fe; voto: a favor)

...promueve la posibilidad de que nuestro Estado laico pueda contar con más y mejores herramientas para construir mayor igualdad de género y mejores políticas de salud pública [...] Está en juego la calidad de nuestra democracia, de nuestro sistema político y de esta institución. (Diputada nacional Laura V Alonso; bloque: Frente para la Victoria; distrito: Buenos Aires; voto: a favor)

¡Es inconcebible que legisladores que provienen de culturas populares y democráticas, piensen que le pueden imponer a la otra mitad del país su voluntad en un sujeto tan íntimo y tan personal que podemos debatirlo años! ¿Pero quienes deciden seguir o no seguir con el embarazo, son las mujeres! ¿Dónde está la democracia? ¿Dónde está el reconocimiento de que el otro no debe pensar igual que nosotros y que el otro es diferente? ¿Me lo explica alguno? (Senador nacional Fernando "Pino" Solanas; bloque: Proyecto Sur; distrito: Ciudad de Buenos Aires; voto: a favor)

En cuarto lugar, la laicidad aparece encuadrada desde una mirada conocida como 
de "laicidad negativa", es decir, la laicidad pensada como un acuerdo de neutralidad para resguardar al Estado de las hegemonías religiosas, entendidas como doctrinarias. En este marco, el laicismo se comprende como una suerte de resistencia por parte de los representantes políticos a la presión ejercida por los grupos religiosos. Debido a la historia del catolicismo integral en Argentina y su capacidad de permear las decisiones estatales $y$, en general, políticas, este marco se manifiesta como anticlerical. Los legisladores que entienden la laicidad como una resistencia a la presión de los grupos religiosos sostienen que los representantes y los dirigentes que forman parte de la esfera política, deben romper relaciones con la esfera religiosa (entendida como "la curia" pero también como las propias creencias individuales) para legislar para toda la sociedad, en especial para los grupos cuyos derechos son vulnerados o no reconocidos. Algunos ejemplos a continuación:

No es nuestro deber sancionar leyes que sean amigables con la curia ni legislar bajo nuestros preceptos de moralidad. No podemos sucumbir a extorsiones de ningún tipo [...] Una religión no puede disponer sobre las políticas públicas en un Estado laico. (Diputada nacional Samanta María Celestes Acerenza; bloque: Propuesta Republicana (PRO); distrito: Buenos Aires; voto: a favor)

Si algo ha distinguido al oscurantismo de la cúpula de la Iglesia católica durante todos estos años es oponerse a leyes como la que hoy estamos discutiendo aquí. Por esos motivos, se han opuesto a la independencia nacional, al fin de la esclavitud, a la Ley 1.420 -de educación común, laica, gratuita y obligatoria-, a la reforma universitaria, al divorcio, a la educación sexual, al matrimonio igualitario, al voto femenino $y$ ahora al derecho al aborto legal. Por eso decimos: ¡basta y exigimos la separación de la Iglesia del Estado! (Diputado nacional Nicolás del Caño; bloque: Partido de los Trabajadores Socialista - Frente de Izquierda; distrito: Ciudad de Buenos Aires; voto: a favor)

Señora presidenta: voy a tener presentes y tratar de seguir al pie de la letra sus instrucciones de velocidad. Las restantes instrucciones me las brindó el señor arzobispo de Buenos Aires Mario Poli desde el púlpito de San Cayetano en el día de ayer. Una de ellas la voy a tener especialmente en consideración y la otra no me va a ser posible. La que voy a asumir es aquella de que los legisladores no interrumpan la tradición de legislar para el bien común. (Senador nacional Ernesto Félix Martínez Carignano; bloque: Cambiemos; distrito: Córdoba; voto: a favor)

En quinto lugar, la laicidad aparece en clave de laicismo, lo cual implica, de acuerdo a la distinción de Bobbio $^{(39)}$ una actitud militante de promoción de la laicidad estatal. Pero además este laicismo aparece, en estos discursos, como un componente clave de la identidad y de las memorias colectivas del radicalismo (Unión Cívica Radical). El hecho de que algunas/os legisladoras/res hayan reforzado sus argumentos a favor de la legalización del aborto movilizando las memorias sobre la Reforma Universitaria de 1918 y destacando el laicismo como un componente central de la identidad radical, se puede entender en el marco de la coyuntura y la alianza política gobernante -desde diciembre de 2015- Cambiemos, debido a que, tal como se ha analizado en diversos trabajos ${ }^{(40,41,42,43)}$, en dicha coalición conviven elementos liberales con otros católicos. A su vez, dado que varios/as legisladores/as pertenecientes a la Unión Cívica Radical o con trayectorias radicales votaron en contra del proyecto de legalización, movilizar memorias laicistas en clave de "verdadera identidad radical" fue un recurso discursivo importante del que se valieron los diputados radicales a favor de la legalización para diferenciarse. La apelación al laicismo como parte central de la identidad radical o reformista implica una forma de dirigirse no solo a la sociedad civil y al cuerpo 
legislativo sino, sobre todo, a la propia coalición oficialista. Por ello, se hicieron varias menciones a una frase del Manifiesto Liminar $^{(44)}$ de la Reforma Universitaria, en el año de su centésimo aniversario, que se hizo muy conocida y reapareció a lo largo del tiempo en las memorias colectivas reformistas: "Desde hoy contamos para el país una vergüenza menos y una libertad más"(44). En algunas de estas apelaciones se refuerza también la idea de una Argentina laica a partir de la memoria de la Ley 1420 de 1884, en cuyo texto no aparece la palabra "laica" y que, sin embargo, es agregada casi siempre al momento de introducirla ${ }^{(36)}$.

...en muchas de las brillantes intervenciones de los colegas diputados de mi bloque se citó la reforma de 1918 porque está a dos días de cumplir cien años [...] Precisamente, desde ese laicismo, al que caracterizo como la corriente de pensamiento que define la independencia del Estado y de la sociedad de la influencia de las religiones y del clero, ocurrió la reforma de 1918. (Diputado nacional Alejandro Carlos Augusto Echegaray; bloque: Unión Cívica Radical; distrito: Buenos Aires; voto: a favor)

Como reformista que soy, el mejor homenaje que podríamos brindar a los reformistas es decir que hoy tenemos menos dolores y más libertades. (Diputado nacional Hugo María Marcucci; bloque: Unión Cívica Radical; distrito: Santa Fe; voto: a favor)

Como reformista que soy, no puedo dejar de recordar que mañana, 15 de junio, se cumplen cien años de la reforma universitaria, un hito en la educación de nuestro país, de gran parte de Latinoamérica y del mundo. [...] Deseo que al finalizar dentro de pocas horas este debate, podamos decir como aquellos jóvenes reformistas del 18, que desde hoy el país cuenta con una vergüenza menos y una libertad más. (Diputado nacional Albor Angel Cantard; bloque:
Unión Cívica Radical; distrito: Santa Fe; voto: a favor)

Hay una Córdoba buena y que ilumina: la de Antonio del Viso, ministro del Interior, senador, gobernador de nuestra provincia, que promovía el registro civil, el matrimonio civil, la separación de la Iglesia del Estado, el que trajo a las maestras normales norteamericanas a la escuela laica. (Senador nacional Ernesto Féliz Martínez; bloque: Cambiemos; distrito: Córdoba; voto: a favor)

Por último, la laicidad apareció en los discursos como un arreglo capaz de garantizar el pluralismo, la libertad de creencias y la igualdad entre estas creencias. Estas configuraciones de la noción de laicidad coinciden en parte con la definición de laicidad de Milot $^{(24)}$ como un acuerdo institucional que implica separación entre las iglesias y el Estado, libertad de conciencia y de expresión, e igualdad entre las distintas "conciencias" y "expresiones" garantizada y protegida por el Estado. La mención a la historia sirvió, en algunos casos, para dar cuenta del pluralismo que se dio en la misma formación de la Argentina moderna con la inmigración, y la necesidad de establecer instituciones laicas para garantizar el respeto de todas las creencias.

Aquellos que sientan, piensen y asuman la religión, seguramente no van a realizar ningún tipo de acción que vulnere las normas religiosas, pero la religión no puede imponerle al conjunto del país y del Estado el pensamiento, la visión religiosa, sobre normas que son de naturaleza civil del Estado laico. Este es el verdadero corazón del debate. (Senador nacional Miguel Ángel Pichetto; bloque: Argentina; distrito: Río Negro; voto: a favor)

El Estado laico en la Argentina, ante la tensión entre el conflicto religioso y la visión laica, no fue fácil. Desde la Ley 1420, con la educación gratuita y laica. Se citó la creación de los registros del 
Estado Civil. Miren, en 1886, o hasta ese año, todo lo que tenía que ver con la vida de las personas se asentaba en los libros parroquiales. Y ¿saben por qué el Estado recuperó ese rol? Porque fueron las corrientes inmigratorias. ¿Ustedes saben lo que implicaba en 1886, para un ciudadano que no profesaba la religión católica, que podía ser evangélico o judío, registrar un nacimiento en un libro parroquial? (Senador nacional Luis Petcoff Naidenoff; bloque: Cambiemos; distrito: Formosa; voto: a favor)

La Argentina [...] desde su Constitución Nacional en adelante ha reconocido la pluralidad cultural; ha reconocido que es un país laico. Este país fue conformado por sucesivos procesos migratorios y civilizatorios de distintas procedencias culturales y en su mestizaje con los pueblos originarios ha dado este pueblo nuevo. (Senador nacional Fernando "Pino" Solanas; bloque: Proyecto Sur; distrito: Ciudad de Buenos Aires; voto: a favor)

¿Qué significa estar en un Estado laico? Significa estar en un Estado donde claramente se separa el ámbito político y social de la Iglesia. ¿Quién pone la frontera? ¿Quién marca el límite? El límite lo marca la ley. ¿En un Estado laico se está en contra de la religión? No, para nada. Al contrario. Porque el Estado laico [...] garantiza la libertad de cultos y su ejercicio. Pero en el Estado laico, los gobiernos y los legisladores tienen que realizar acciones positivas para todos los ciudadanos, para garantizar los derechos individuales, los derechos colectivos, las garantías constitucionales, para garantizar la diversidad. Eso lo hace un Estado laico. (Senadora nacional Magdalena Odarda; bloque: RIO; distrito: Río Negro; voto: a favor)

\section{Concepciones de laicidad en espacios de activismos feministas}

En los talleres de "Mujeres y Estado laico" y de "Mujeres y religiones" de cada Encuentro Nacional de Mujeres que analizamos, los temarios sugeridos son similares e incluyen primordialmente aspectos negativos o controversiales de las iglesias y religiones, como la relación con el patriarcado, la pedofilia, el financiamiento estatal de la Iglesia católica, la utilización de la objeción de conciencia para obstaculizar el ejercicio de los derechos sexuales y reproductivos, la injerencia religiosa en el poder judicial, la salud y la educación públicas, la discriminación y violencia contra las mujeres, las organizaciones no gubernamentales antilegalización del aborto, etcétera. Solo en taller de "Mujeres y religiones" se enuncia como tema la "diversidad de ideas y posiciones dentro de las Iglesias" y la vinculación de los movimientos religiosos con otros movimientos; y en los talleres de "Terapias alternativas" surge entre las asistentes la pregunta en torno a la posibilidad de ser espiritual y ser feminista. La misma inquietud registramos en los talleres de espiritualidad de los ERMLTT. Dicho interrogante se sumaba al cuestionamiento de los binarismos que recrean la idea de "energías femeninas y masculinas" y el esencialismo del poder femenino asociado a la menstruación.

Más allá de las temáticas propuestas, las diferencias surgen en los tonos de las discusiones y los perfiles de las participantes. En los talleres sobre Estado laico predomina la desafiliación religiosa institucional y/o personal -o el deseo de hacerlo-; y en los de religiones y espiritualidades, la búsqueda de una conciliación entre la militancia feminista y las propias creencias.

En "Mujeres y religiones" la mayoría de las asistentes ha tenido o tiene vínculos con iglesias católicas y evangélicas, exponen sus críticas a la posición que estas asignan a las mujeres, a la vez que cuestionan los discursos censuradores de estas instituciones sobre la libertad sexual y reproductiva. Sin embargo, para ellas conectarse con lo espiritual y lo trascendente es algo propio del ser humano 
y un valor en sus vidas al que no quieren renunciar. Circulan entonces referencias a la teología feminista, a pastores/as y sacerdotes "progres", como posibles respuestas a la pregunta que algunas formulan con angustia: ¿Cómo conciliar ser feminista, lesbiana, "disidente sexual" y pertenecer a una iglesia o definirse como espiritual? No están ausentes el cuestionamiento al financiamiento que la Iglesia católica recibe del estado, los "curas abusadores", la intromisión de las iglesias en las políticas de sexualidad o las formas de lograr la apostasía, pero esto no es lo distintivo del Taller. Más que una definición de laicidad lo que surge es una de lo religioso/ espiritual como potencia feminista, y en ese sentido, aunque no se explicita, la laicidad debería asegurar la convivencia social.

...yo quiero seguir perteneciendo, buscar espacios de resistencia [...] asumir el desafío de quedarme. (ENM de 2016, taller "Mujeres y religiones")

...no puede haber una revolución feminista sin una revolución espiritual [...] hay que reclamar espacio en las religiones, pero también generar una espiritualidad propia, feminista, de mujeres. (ENM de 2017, taller "Mujeres y religiones")

Cuando nos miran el culo por la calle no nos preguntan de qué religión somos [...] no hay que tener miedo por la fe. Podemos en nombre de Cristo pedir la legalización del aborto. (ENM de 2017, taller "Mujeres y religiones")

[Ante actos frente a la Catedral] a los legisladores hay que reclamar (ENM de 2017, taller "Mujeres y religiones")

En varios relatos, las iglesias se posicionan como un lugar de encuentro que no debería atacarse. De ahí que rechacen, en general, pintadas en las paredes de la Catedral de cada lugar o intervenciones, debido a que, para las mujeres que concurren a estos talleres, la laicidad implica un reconocimiento, a través de la separación entre Iglesia y Estado, de la libertad de creer y no creer. Es decir, construyen una mirada no antirreligiosa de la laicidad. Esta concepción se acerca a la definición de Blancarte quien entiende a la laicidad:

...estrechamente emparentada con el liberalismo, con la democracia, con la separación de esferas entre lo religioso y lo político, con la tolerancia religiosa, con los derechos humanos, con la libertad de religión y de creencias y con la modernidad política, sin asimilarse a ninguna de estas. En términos funcionales, la laicidad es un régimen de convivencia diseñado para el respeto de la libertad de conciencia, en el marco de una sociedad crecientemente plural, o que reconoce una diversidad existente. ${ }^{(45)}$

En los talleres de "Mujeres y Estado laico", por el contrario, este se piensa en oposición a un estado confesional. La separación Estado e Iglesia es la principal característica de la definición de laicidad que allí se propone. La crítica se concentra en la normatividad jurídica (artículo 2 de la Constitución Nacional, especialmente), las subvenciones a las escuelas religiosas, el silencio clerical ante la pedofilia y la presencia de símbolos religiosos en el espacio público. En general, no circula información científica sobre la historia de la laicidad como concepto o proceso, ni sobre cómo se calculan los aportes estatales a la Iglesia católica; tampoco se desarrollan propuestas concretas y viables que permitan sostener el sistema educativo privado confesional sin esos fondos. Tampoco se desarrollan argumentos a la pregunta introducida por nosotras sobre qué hacer ante la presencia de símbolos religiosos populares en el espacio público, como los altares al Gauchito Gil. El planteo que tiene mayor consenso es distinguir entre la libertad de cultos y que el culto lo sostenga económica y políticamente el Estado. "¿Por qué hay que creer en algo?" dice una feminista atea, fundadora de estos talleres, quien propone ir un paso más adelante y crear el taller "Mujeres y ateísmo". Esta es una de las posiciones predominantes 
y solo esporádicamente se escucha alguna voz que diferencia ser atea y ser laicista.

La apostasía como estrategia política, pero también como reparación subjetiva, es una de las prácticas que más se comenta y promociona. Se proponen campañas de sensibilización para que las personas no bauticen a sus hijos como un tipo de proselitismo antieclesial. Las participantes que ya apostaron explican el procedimiento y proponen fechas comunes para que el acto individual de apostatar se vuelva colectivo.

Habría que prohibir el saludo de la navidad [...] también me molesta la cruz de la Iglesia porque, aunque no quiera cuando camino por la calle, la veo. (ENM de 2015, taller "Mujeres y Estado laico")

Propongo que en la enseñanza de la historia se deje de periodizar con el nacimiento de Cristo como fecha de corte. (ENM de 2015, taller "Mujeres y Estado laico")

Bautizar a un bebé que no tiene capacidad de decidir es como una violación a los derechos humanos. (ENM de 2016, taller "Mujeres y Estado Laico")

¿Por qué hay que creer en algo? (ENM de 2016, taller "Mujeres y Estado Laico")

Me chupa un pecho / si el papa es argentino / si el papa es europeo o multinacional / lo que yo quiero es el derecho al aborto / que se acaben la trata el machismo y la opresión patriarcal / Pido justicia por estos cinco siglos, saqueo y femicidio que vos siempre avalás. (Cancionero de la Campaña Nacional por el Derecho al Aborto Legal, Seguro y Gratuito, 2017)

La única Iglesia que ilumina es la que arde. (Stencil que puede verse en las calles que recorren las marchas de cierre de cada ENM)
En los actos de apertura y, principalmente, en las marchas que cierran cada Encuentro, carteles, pintadas sobre las paredes de edificios y sobre el propio cuerpo de las participantes reclaman el Estado laico asimilado a la separación entre Estado e Iglesia, y también hacen una apelación más personal con frases como "Saquen sus rosarios de nuestros ovarios" y el giro radical en el stencil que muestra una iglesia en llamas con la frase anarquista "La única Iglesia que ilumina es la que arde" que, en el Encuentro Nacional de Mujeres de 2005, el colectivo de artistas feministas Mujeres Públicas colocó en cajitas de fósforos y que se repite en cada nuevo encuentro en pintadas en las paredes (Figura 1). Durante la marcha, las columnas suelen dividirse y una gran parte de las concurrentes pasan por delante de la Catedral de cada ciudad

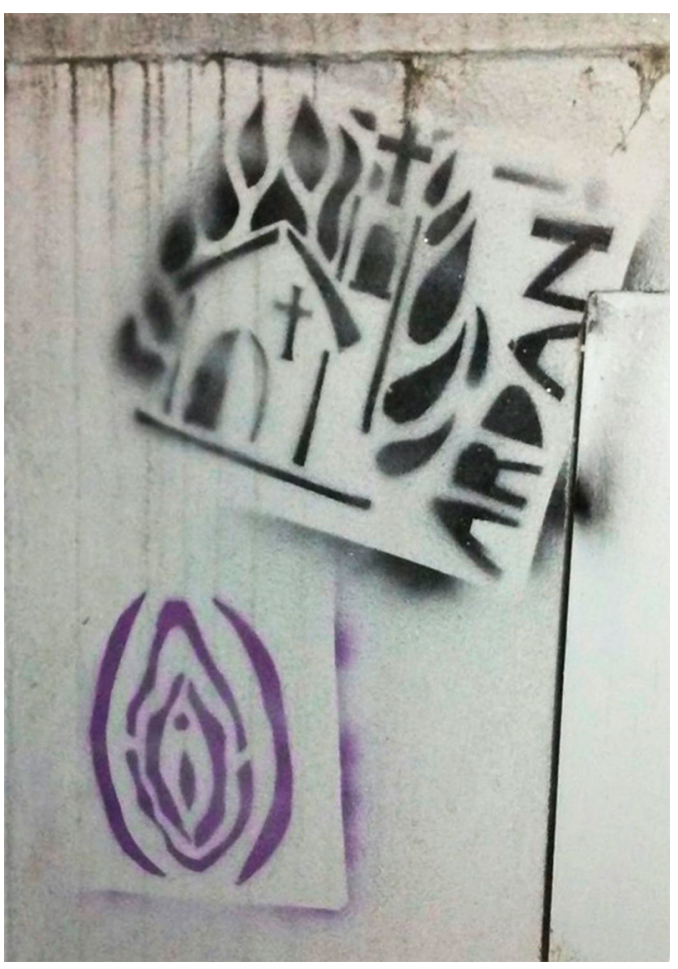

Figura 1. Stencil sobre las paredes de la ruta que se recorre en la marcha de cierre. Encuentro Nacional de Mujeres, Rosario, 2016.

Foto: Karina Felitti. 
para gritar y pintar en las vallas o paredes del edificio estas y otras consignas, que ponen en una misma línea a la Iglesia católica, el patriarcado y los gobiernos antidemocráticos como en el grito: "ilglesia, basura, vos sos la dictadura!".

Se manifiesta así una idea de laicidad anticlerical. De acuerdo a Milot ${ }^{(24)}$ este tipo de laicidad se configura en países donde las religiones o iglesias enmarcaron, durante el proceso de conformación del Estado nacional, las diversas expresiones de la vida social. Pero más allá de estas situaciones históricas -que en algunos países se tradujeron en la persecución del clero y los laicos, y la expropiación de templos y otros espacios y reliquias- el discurso del laicismo anticlerical se caracteriza por la denuncia del poder de la Iglesia católica, de los recursos públicos de los que se vale, de su influencia sobre el Estado y la clase política, y su carácter reactivo ante el poder eclesiástico, sobre todo, católico.

Carteles, pintadas en las paredes y el pavimento, escritos sobre el cuerpo de las más jóvenes, canciones, declaraciones, y la presencia del pañuelo naranja o negro en el $8 \mathrm{M}$, del mismo modo que la comercialización, en varios puestos de la feria del ERMLTT de La Matanza, de pañuelos naranjas y pines (Figura 2) y hasta un pastel decorado con esos motivos (Figura 3), confirmaban una concepción de la laicidad concentrada en la separación Estado e iglesias y, a la vez, un marcado anticlericalismo.

Un punto de contraste interesante con esta postura es que muchos de los productos (libros, fanzines, remeras estampadas, calcos, agendas) que se comercializan en las plazas durante estos mismos eventos remiten a elementos espirituales y se alejan de una posición que ve incompatible el creer en fuerzas trascendentes (diosas, naturaleza, cosmos, energías) y actuar políticamente como feministas; por el contrario lo espiritual es presentado como una forma de activismo que puede incluso reivindicar el derecho al aborto $^{(46)}$.

En paralelo a los planteos más anticlericales, sus mismas voceras reconocen el trabajo de las "católicas feministas" de la Campaña,

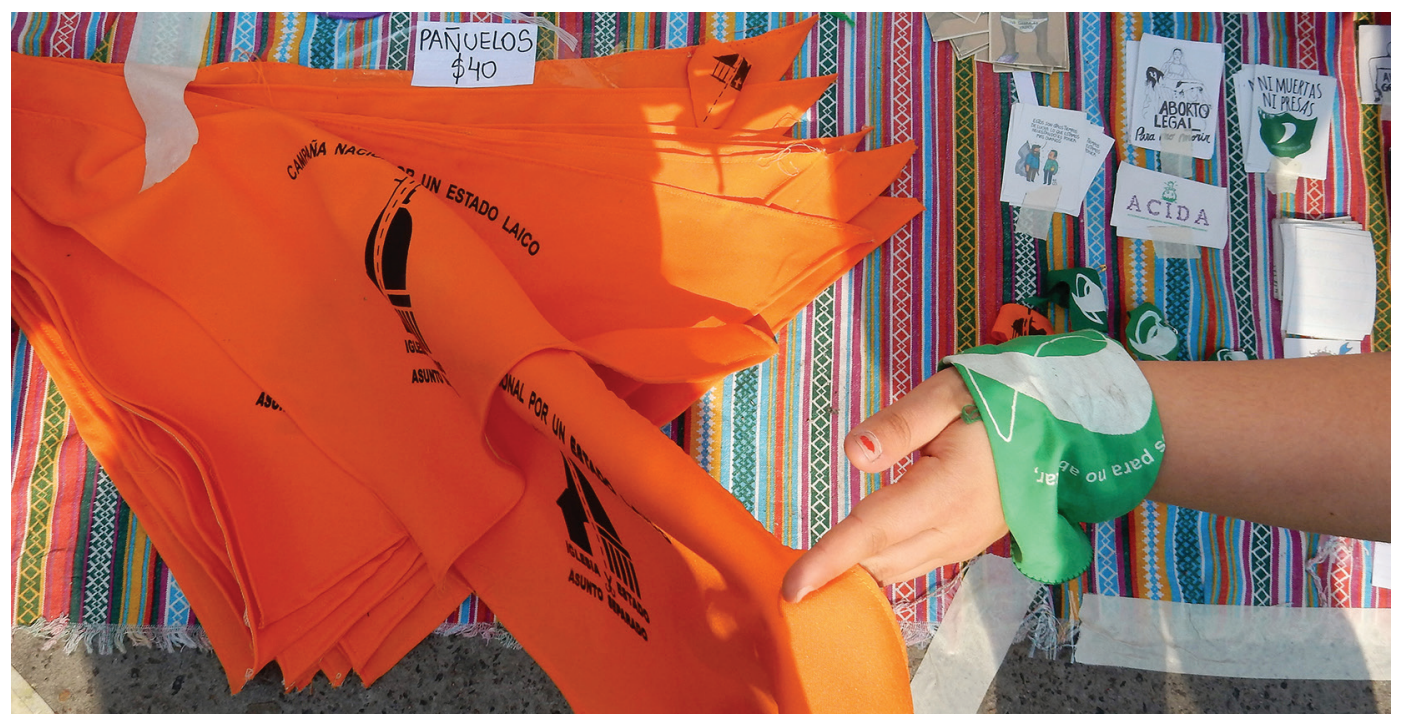

Figura 2. Pañuelos naranjas y pines de la "Campaña por un Estado laico". Feria de productos del Encuentros Regionales de Mujeres, Lesbianas, Travestis y Trans (ERMLTT), La Matanza, 8 de diciembre de 2018.

Foto: Karina Felitti. 


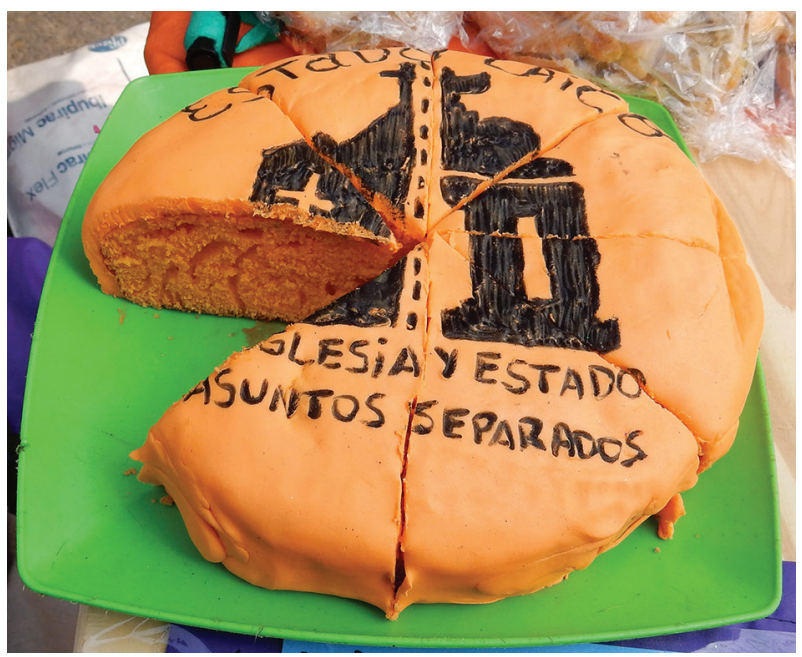

Figura 3. Pastel decorado con la leyenda "Estado laico, iglesia y Estado, asuntos separados". Feria de productos del Encuentros Regionales de Mujeres, Lesbianas, Travestis y Trans (ERMLTT), La Matanza, 8 de diciembre de 2018.

Foto: Karina Felitti.
Las mujeres fuimos las primeras sanadoras. Nos quemaron por brujas por eso. (ERMLTT, 2016, taller “Teología y espiritualidades")

Recomiendo los libros de Ginecología natural y el de Luna Roja para poder conocer nuestros cuerpos y empoderarnos. Debemos reconectar con la ciclicidad femenina. (ENM 2017, taller "Terapias alternativas")

Hay que recuperar el poder energético, colectivo, antipatriarcal. (ERMLTT, 2017, taller "Teología y espiritualidades")

Vemos cuerpos luchadores pero hechos pelota [...] hay que poder reconectar para sanar. (ERMLTT, 2017, taller "Teología y espiritualidades")

Lo que no respeta las decisiones de cada une no es feminista. (ERMLTT, 2017, taIler "Teología y espiritualidades")

\section{CONCLUSIONES} bre brujas y sanadoras, ginecología natural, remeras, calcos, agendas y cuadernos que retoman estos tópicos, celebraciones rituales y actos performáticos que conectaban demandas políticas con "intenciones" ancladas en el plano espiritual y la celebración de la figura de la bruja como arquetipo de poder femenino. En ese sentido, en los talleres de "Espiritualidades" y de "Terapias alternativas" la apuesta a la sanación es simbólica y material, en tanto se recomiendan plantas medicinales y tratamientos naturales, en una crítica que enfoca más en el sistema médico "patriarcal" que en las iglesias. En estos espacios se insiste en el poder político de la espiritualidad y en la necesidad de respetar las prácticas y creencias de cada mujer como principio feminista:

Hay que separar la espiritualidad de la Iglesia católica. (ERMLTT, 2017, taller "Teología y espiritualidades")
Los materiales analizados en este artículo nos permiten confirmar la existencia de diferentes configuraciones de la laicidad que parten de un punto en común que es la separación entre Estado e Iglesia y, a la vez, colocan el énfasis en distintos aspectos de la relación entre Estado, religiones, creencias y democracia. Durante las discusiones sobre el proyecto de interrupción voluntaria del embarazo en la Cámara de Diputados (13 y 14 de junio de 2018) y en la Cámara de Senadores (8 agosto de 2018) distinguimos seis configuraciones, que pudieron también combinarse.

En algunos discursos la laicidad apareció como una característica del Estado argentino. La idea de una "república laica" que Mallimaci entiende como parte de una mitología, impulsó un voto positivo para continuar con esta tradición; pero también, en algunos casos, justificó el voto en contra. Contrariamente a 
lo que la mayoría de los activismos por el Estado laico sostienen, respecto a la confluencia de la laicidad con los derechos sexuales y reproductivos, en los discursos de algunos/ as legisladores/as nacionales que votaron en contra del proyecto, encontramos referencias a la laicidad del Estado. En estos casos, la separación de sus creencias religiosas no fue un obstáculo para posicionarse en contra, ya que apelaron a un discurso secular: la obligación del Estado de defender el derecho a la vida como derecho humano, en este caso, el derecho del no nacido.

En otros casos, el diagnóstico es el opuesto y la laicidad es todavía un proyecto sobre el que hay que trabajar: aprobar la interrupción voluntaria del embarazo sería un importante paso en ese sentido. En una línea similar, la laicidad se propone como herramienta que sostiene la democracia y defiende el pluralismo, característico también de la historia argentina, en tanto algunas medidas como la obligatoriedad y gratuidad de educación pública -que se presenta como laica- y la creación del registro civil en la década de 1880, tenían como objetivo integrar a la inmigración.

Como contrapartida, se asume que los poderes religiosos no quedaron inertes a esta avanzada del proceso de laicización estatal y por eso resulta necesario un modelo de laicidad negativa que roza muchas veces lo anticlerical. Asimismo, la memoria de un laicismo histórico es una forma de consolidar una identidad partidaria, en el caso de la Unión Cívica Radical que hoy es parte de la coalición gobernante, y de establecer diferencias al interior de este partido entre quienes defienden la legalización del aborto y quienes no lo hacen. Por último, reunimos argumentos que proponen con más fuerza la separación entre Estado e iglesias, la necesidad de distinguir entre las convicciones personales y el deber de la función pública $y$, al mismo tiempo, garantizar la libertad de conciencia.

En los activismos feministas encontramos dos visiones claramente demarcadas y una tercera que establece una situación dilemática aun en términos teóricos pero que, en la práctica, parece resolverse de manera individual más que colectiva. Por un lado, en cada Encuentro Nacional de Mujeres y ERMLTT circula un discurso que asocia la laicidad con la separación del Estado de las iglesias. Los dibujos en los pañuelos naranjas muestran un edificio con una cruz -que se separa del edificio del Congreso con una línea punteada de corte- que puede representar tanto a la Iglesia católica como a las evangélicas, pero otras referencias (como "curas pedófilos", subvenciones a escuelas católicas, críticas al papa Francisco y al Vaticano, vínculos de la Iglesia católica con la última dictadura cívico militar) enfocan la denuncia en el campo católico. En las versiones más radicales, la laicidad se mimetiza con el anticlericalismo y una propuesta de apostasía e incluso de ateísmo, como puede verse en algunos dibujos y en las discusiones de los talleres con el tema Estado laico.

En los talleres que problematizan los vínculos de las mujeres con las religiones y las espiritualidades, en cambio, las participantes coinciden en la necesidad de separar el Estado de las iglesias, pero no rechazan adherir a una creencia. Por el contrario, algunas llegan a encontrar en la afiliación religiosa y la práctica espiritual una plataforma política desde la cual demandar el derecho al aborto. En estos casos, si bien no se habla explícitamente de laicidad, se entiende que el Estado debería garantizar el derecho a creer y no creer y, de paso, que los feminismos también deberían hacerlo.

La creciente presencia del discurso de la laicidad en la política, ya sea parlamentaria o feminista, invita a seguir preguntándonos qué entienden los actores sociales por laicidad, con cuáles modelos la asocian, cómo piensan a partir de ella la equidad de género, el pluralismo religioso, la convivencia social o, en términos más amplios, la democracia. En este artículo presentamos algunas configuraciones de laicidad que no se dejan encorsetar fácilmente en tipos ideales, dado que la laicidad es siempre proceso y, a su vez, analizadas desde un enfoque de género, ponen al descubierto algunas tensiones entre la idea de un Estado laico, necesariamente garante 
de la equidad de género, y la incompatibilidad de una adscripción religiosa y/o espiritual y la militancia feminista.

\section{AGRADECIMIENTOS}

Esta investigación contó con el apoyo del Fondo para la Investigación Científica y Tecnológica (FONCyT), desde el 01/2016 al 12/2018, para el proyecto "Religión y política en la Argentina democrática: Permeabilidades laicas y confesionales en la normatividad jurídica, las políticas públicas y la cultura política".

\section{REFERENCIAS BIBLIOGRÁFICAS}

1. Pecheny M, De la Dehesa R. Sexualidades y política en América Latina: el matrimonio igualitario en contexto. En: Aldao M, Clericó L, (coords.). Matrimonio igualitario: perspectivas sociales, políticas y jurídicas. Buenos Aires: Eudeba; 2010. p. 11-62.

2. Tarducci M. La iglesia católica y los encuentros nacionales de mujeres. Revista Estudos Feministas. 2005;13(2):397-402.

3. Masson L. Feministas en todas partes: una etnografía de espacios y narrativas feministas en Argentina. Buenos Aires: Prometeo; 2007.

4. Angenot M. El discurso social: Los límites históricos de lo pensable y lo decible. Buenos Aires: Siglo XXI Editores; 2010.

5. Ramos S, Romero M, Aizemberg L. Women's experiences with the use of medical abortion in a legally restricted context: the case of Argentina. Reproductive Health Matters. 2014;44(1):4-15.

6. Burton J. De la comisión al socorro: trazos de militancia feminista por el derecho al aborto en Argentina. Descentrada. 2017;1(2):e020

7. Zurbriggen R, Trpin M, Grosso B. Decidir abortar y decidir acompañar: Socorro Rosa: Un servicio de prácticas y experiencias en clave feminista. En: Zurbriggen R, Anzorena C, (comps.). El aborto como derecho de las mujeres: Otra historia es posible. Buenos Aires: Herramienta; 2013. p. 303-320.
8. Bessone PG. Activismo católico antiabortista en Argentina: performances, discursos y prácticas. Sexualidad, Salud y Sociedad (Rio de Janeiro). 2017;(26):38-67.

9. Vaggione JM. Los roles políticos de la religión. Género y sexualidad más allá del secularismo. En: En nombre de la vida. Vasallo M, (ed.). Buenos Aires: Católicas por el Derecho a Decidir; 2005. p. 137-167.

10. Faúndes JMM, Defago AP. ¿Defensores de la vida?, ¿de cuál "vida"?: un análisis genealógico de la noción de "vida" sostenida por la jerarquía católica contra el aborto". Sexualidad, Salud y Sociedad (Rio de Janeiro). 2013;(15):10-36.

11. Felitti K. L'avortement en Argentine: Politique, religion et droits humains. Autrepart: Revue du Sciences Sociales du Sud. 2015;(70):73-90.

12. Felitti K. Estrategias de comunicación del activismo católico conservador frente al aborto y el matrimonio igualitario en la Argentina. Revista Sociedad y Religión. 2011;(34/35):92-122.

13. Vacarezza N. Política de los afectos, tecnologías de visualización y usos del terror en los discursos de los grupos contrarios a la legalización del aborto. Papeles de Trabajo. 2012;6(10):46-61.

14. Laudano C. Reflexiones en torno a las imágenes fetales en la esfera pública y la noción de "vida" en los discursos contrarios de la legalización del aborto. Temas de Mujeres-Revista del CEHIM. 2012;8(8):58-68.

15. Irrazábal G. Bioeticistas católicos en contra de las técnicas de reproducción asistida: Implicancias para la futura Reforma del Código Civil Argentino. Revista Derecho de Familia. 2012;(57):113-134.

16. Irrazábal G. El derecho al aborto en discusión: la intervención de grupos católicos en la comisión de salud de la legislatura de la ciudad de Buenos Aires. Sociologias. 2010;12(24):308-336. 
17. Jones D, Dulbecco P. El Papa Francisco y el derecho al aborto: ¿Del pesimismo de la razón y el optimismo de la voluntad al puro pesimismo? En: Renold JM, Frigerio A, (comp.). Visiones del Papa Francisco desde las Ciencias Sociales. Rosario: Editorial de la Universidad Nacional de Rosario; 2014. p. 41-50.

18. Prieto S. El fin del mundo: El fenómeno del papa Francisco desde la sociología. Villa María: Eduvim; 2016.

19. Jones D, Peñas Defago A, Godoy-Anativia M, (eds.). Religiones, matrimonio igualitario y aborto: alianzas con y entre actores religiosos por los derechos sexuales y reproductivos en Argentina. Córdoba: Ferreyra Editor, CDD, NYU; 2013.

20. Felitti K, Irrazábal G. Los no nacidos y las mujeres que los gestaban: significaciones, prácticas políticas y rituales en Buenos Aires. Revista de Estudios Sociales. 2018;(64):125-137.

21. Bosio MT, Johnson MC, Frencia MM. Disidencia religiosa y libertad de conciencia: católicas que deciden abortar. RevIISE. 2018;11(11):99-107.

22. Bessone PG. Experiencia aborto y maternidad en las católicas feministas. Nomada: Revista Crítica de Ciencias Sociales y Jurídicas. 2012;34(2):149162.

23. Prieto S. Confesionalidad legal y confesionalidad política: hacia una subtipología de la laicidad. En: I Congreso Latinoamericano de Teoría Social. Ciudad de Buenos Aires: Instituto de Investigaciones Gino Germani, Facultad de Ciencias Sociales, Universidad de Buenos Aires; 2015.

24. Milot M. La laicidad. Madrid: Editorial CCS; 2009.

25. Esquivel JC. Religious and politics in Argentina: Religious influence on parliamentary decisions on sexual and reproductive rights. Latin American Perspectives. 2016;(43)3:133-143.

26. Prieto S, Mosqueira M. Laicidad argentina, laicidad subsidiaria: un análisis comparativo de los casos de la ciudad y la provincia de Buenos Aires. Revista Ciencias Sociales. 2015;(88):40-45.

27. Prieto S. Religión y espacio público en la Ciudad de Buenos Aires: Igualdad de cultos, libertad de conciencia y autonomía en el debate sobre los capellanes y las religiosas en los hospitales porteños. Igualdad, Autonomía Personal y Derechos Sociales. 2017;(5):125-157.

28. Prieto S. Memorias colectivas, ideas de provincia y catolicismo en el debate parlamentario de la última ley de educación de Córdoba, Argentina (2010). Anuario de Historia Regional y de las Fronteras. 2018;23(2):173-198.

29. Scott J. W. Sex and secularism. New Jersey: Princeton University Press; 2017.

30. Fraser N. La justicia social en la era de la política de la identidad: redistribución, reconocimiento y participación. Revista de Trabajo. 2008; 4(6):83-99.

31. Vaggione JM, Jones D. Religiones y políticas sexuales: Iglesias católica y evangélicas frente al "matrimonio homosexual" en Argentina. En: Gutiérrez Martínez D, Felitti K, (coord.). Diversidad, sexualidades y creencias: cuerpo y derechos en el mundo contemporáneo. Buenos Aires: Prometeo; 2015. p. 219-269.

32. Pecheny M. Parece que no fue ayer: el legado político de la Ley de Divorcio en perspectiva de derechos sexuales. En: Gargarella R, Murillo MV, Pecheny M, (comps.). Discutir Alfonsín. Buenos Aires: Siglo XXI Editores; 2010. p. 85-113.

33. Carbonelli M, Felitti K, Mosqueira M. Religión, sexualidad y política en la Argentina: intervenciones católicas y evangélicas en torno al aborto y el matrimonio igualitario. Revista del Centro de Investigación. 2011;9(36):25-43.

34. Alonso P. De medios ordinarios y extraordinarios: La Iglesia católica y los debates sobre la "muerte digna" en Argentina. Religão e Sociedade. 2014;34(1):122-145.

35. Prieto S. Bioética y catolicismo en la Argentina: Un análisis en base a seis campos en disputa. Religião \& Sociedade. En edición 2018.

36. Mallimaci F. El mito de la Argentina laica: Catolicismo, política y Estado. Buenos Aires: Capital Intelectual; 2015.

37. Honorable Cámara de Diputados de la Nación. 8a Reunión, 7a Sesión Extraordinaria [Internet]. Diario de Sesiones; 13/06/2018 [citado 1 sep 2018]. Disponible en: https://tinyurl.com/ ycvm $45 \mathrm{q} 7$.

38. Honorable Senado de la Nación Argentina. 10a Reunión, 5a Sesión Especial, 8 y 9 de agosto de 2018 [Internet]. Sesión especial; 8/08/2018 [citado 1 sep 2018]. Disponible en: https://tinyurl. com/y7x7ryje.

39. Bobbio N. Cultura laica y laicismo. Iglesia Viva: Revista de Pensamiento Cristiano. 2005;(222):147149. 
40. Vommaro G, Morresi S. "Hagamos equipo": PRO y la construcción de la nueva derecha en Argentina. Los Polvorines: UNGS; 2015.

41. Vommaro G, Morresi S, Bellotti A. Mundo PRO: Anatomía de un partido fabricado para ganar. Buenos Aires: Planeta; 2015.

42. Gessaghi V. La educación de la clase alta argentina. Buenos Aires: Siglo XXI Editores; 2016.

43. Cruz F. Socios pero no tanto: Partidos y coaliciones en Argentina, 2003-2015. Buenos Aires: Eudeba. En edición 2018.

44. Barros EF, Valdés $H$, Bordabehere IC, Sayago G, Castellanos A, Méndez LM, et al. Manifiesto li- minar [Internet]. 21 jun 2018 [citado 10 jul 2018]. Disponible: https://tinyurl.com/yapg55vf.

45. Blancarte R. América Latina: entre pluri-confesionalidad y laicidad. Civitas: Revista de Ciencias Sociais. 2011;11(2):182-206.

46. Felitti K. Nuevas espiritualidades y feminismos: diálogos y tensiones. En: Laboratorio de observación del fenómeno religioso en la sociedad contemporánea "Nuevas espiritualidades y feminismos: diálogos y tensiones" [Internet]. México DF: Universidad Nacional Autónoma de México; 2018 [citado 1 sep 2018]. Disponible en: https://tinyurl.com/ y7aaa7kb.

\section{FORMA DE CITAR}

Felitti K, Prieto S. Configuraciones de la laicidad en los debates por la legalización del aborto en la Argentina: discursos parlamentarios y feministas (2015-2018). Salud Colectiva. 2018;14(3):405-423. doi: 10.18294/sc.2018.2027.

Recibido: 29 de junio de 2018 | Versión final: 30 de agosto de 2018 | Aprobado: 16 de septiembre de 2018

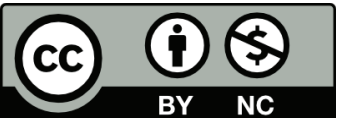

Este obra está bajo una licencia de Creative Commons Reconocimiento-NoComercial 4.0 Internacional. Reconocimiento - Permite copiar, distribuir y comunicar públicamente la obra. A cambio, se debe reconocer y citar al autor original. No Comercial - Esta obra no puede ser utilizada con finalidades comerciales, a menos que se obtenga el permiso. 